\title{
A Compact Wideband Crossover Coupler with Lumped Elements
}

\author{
Kwangwon Park ${ }^{1} \cdot$ Hyunkyu Lee ${ }^{1} \cdot$ Iljin Lee $^{1} \cdot$ In-Woong Kang $^{2} \cdot$ Sanggeun Jeon ${ }^{1, *}$
}

\begin{abstract}
A compact wideband crossover coupler with fully lumped elements is presented. To achieve a wideband operation, a three-section branch-line structure is employed for the crossover coupler. The size is significantly minimized by replacing transmission lines with lumped elements. The measurement shows that the insertion loss, isolation, and return loss are $1.7 \mathrm{~dB}, 24 \mathrm{~dB}$, and $14.5 \mathrm{~dB}$, respectively, at $2 \mathrm{GHz}$. The fractional bandwidth of $20-\mathrm{dB}$ isolation and $3-\mathrm{dB}$ insertion loss is $27 \%$. The size of the crossover coupler is $11 \mathrm{~mm} \times 9$ $\mathrm{mm}$, which corresponds to $0.07 \lambda \times 0.06 \lambda$ at $2 \mathrm{GHz}$. This is significantly smaller than a conventional three-section branch-line crossover coupler by $95 \%$.
\end{abstract}

Key Words: Butler Matrix, Crossover Coupler, Lumped Elements, Planar Circuits.

\section{INTRODUCTION}

A crossover coupler is an indispensable passive component in microwave systems. Specifically, a Butler matrix is an example of a beamforming network that requires a crossover coupler, as shown in Fig. 1. Array antennas are connected to the Butler matrix consisting of $3-\mathrm{dB}$ quadrature hybrids, $45^{\circ}$ phase shifters, and crossover couplers, so that the antenna beam is formed and steered electronically.

The crossover coupler makes two signals cross each other while maintaining a high degree of isolation. As the crossover coupler occupies a substantial area in the Butler matrix [1], size reduction is a critical issue in the coupler design.

Traditionally, the signal crossover was achieved by air-bridges or under-passes based on a multilayer printed circuit board (PCB) $[2,3]$. However, those methods lead to non-planar structures, and increase the fabrication cost and difficulty. Thus, several fully planar configurations have been proposed for crossover applications [4-9]. A symmetrical four-port double-ring structure was reported in $[4,5]$. A planar crossover was achieved by cascading two branch-line structures in [6]. The number of branch-line structures connected in cascade was increased to more than three in order to improve the operation bandwidth in [7].

However, most of the previous crossover couplers are bulky because they are based on quarter-wave transmission lines. To make the crossover smaller, a part of the transmission lines was shortened by connecting a shunted open stub at each end of the lines [8]. A dual-band crossover coupler was also proposed as a variation of the branch-line structure [9]. Nonetheless, all of these structures are still large and occupy a significant $\mathrm{PCB}$ area.

In this paper, a new compact wideband crossover coupler is presented. A three-section branch-line structure is employed for

Manuscript received September 16, 2018 ; Revised November 9, 2018 ; Accepted December 8, 2018. (ID No. 20180916-066J)

${ }^{1}$ School of Electrical Engineering, Korea University, Seoul, Korea.

${ }^{2}$ Agency for Defense Development, Daejeon, Korea.

"Corresponding Author: Sanggeun Jeon (e-mail: sgjeon@korea.ac.kr)

This is an Open-Access article distributed under the terms of the Creative Commons Attribution Non-Commercial License (http://creativecommons.org/licenses/by-nc/4.0) which permits unrestricted non-commercial use, distribution, and reproduction in any medium, provided the original work is properly cited.

(c) Copyright The Korean Institute of Electromagnetic Engineering and Science. All Rights Reserved. 


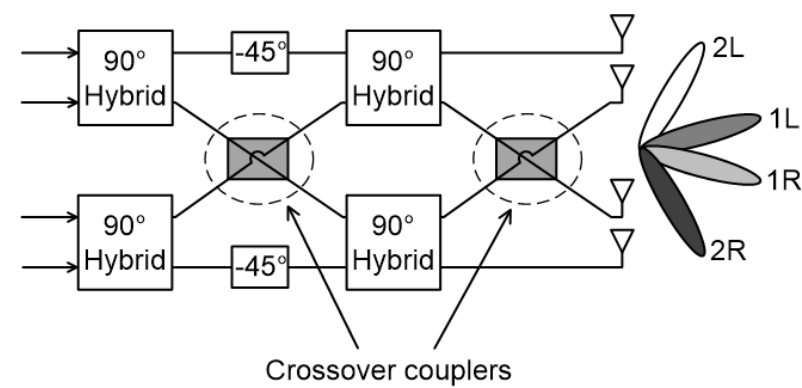

Fig. 1. Configuration of $4 \times 4$ Butler matrix.

wideband operation. To reduce the size, all quarter-wave transmission lines are replaced by lumped components using the $\pi^{-}$ equivalent model. In Section II, a fully-lumped crossover coupler is proposed. In Section III, the coupler is designed at 2 $\mathrm{GHz}$ for the purpose of demonstration, followed by the experimental results given in Section IV.

\section{FULLY-LUMPED CROSSOVER COUPLER}

A conventional wideband crossover coupler based on a threesection branch-line structure [7] is shown in Fig. 2. The lengths of transmission lines are all quarter-wave, and the characteristic impedances are given by

$$
Z_{1}=Z_{c}, Z_{3}=Z_{4}=\frac{2 Z_{2}^{2}}{Z_{1}}
$$

where $Z_{c}$ is the port impedance. $Z_{2}$ should be chosen considering the input matching and isolation performance, which was $40 \Omega$ in [7]. However, the size of the conventional crossover coupler is large because all of the transmission lines are quarterwave long. The electrical length of the lines are reduced by connecting the shunted open stubs in [8]. Nonetheless, the physical length of the lines is still large and becomes even larger as the operating frequency decreases.

In this work, the quarter-wave transmission lines in Fig. 2 are replaced fully by lumped components. Therefore, the size of the crossover coupler is not only significantly reduced but also is independent of the operating frequency. Fig. 3 shows the $\pi^{-}$ equivalent lumped model of a transmission line. The values of the lumped components are given by [10],

$$
\begin{gathered}
L_{s}=\frac{\sin \theta}{2 \pi f} \\
C_{p}=\frac{1}{2 \pi f Z} \sqrt{\frac{1-\cos \theta}{1+\cos \theta}}
\end{gathered}
$$

where $Z$ and $\theta$ are the characteristic impedance and electrical length of the transmission line, and $f$ is the operation frequency.

Fig. 4(a) shows an initial version of the proposed lumped crossover coupler where each transmission line $\left(Z_{i}, 1 \leq i \leq 4\right)$

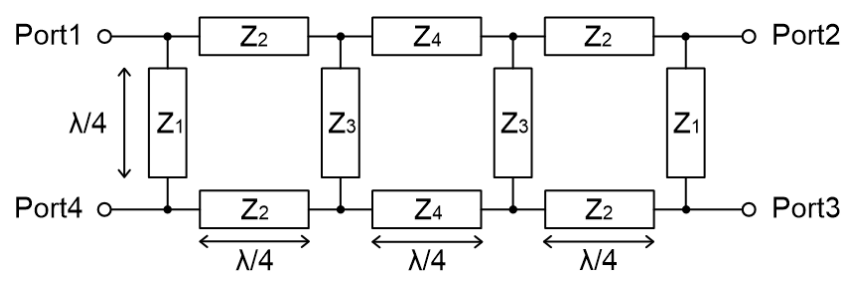

Fig. 2. Conventional crossover coupler based on three-section branch-line structure.

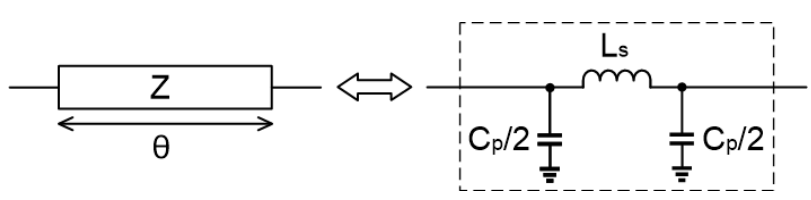

Fig. 3. $\pi$-equivalent lumped model of transmission line.

is replaced by one inductor $\left(L_{i}\right)$ and two capacitors $\left(C_{i} / 2\right)$. As the lines are quarter-wave long $\left(\theta=90^{\circ}\right)$, the lumped component values are derived from Eqs. (2) and (3):

$$
\begin{gathered}
L_{i}=\frac{Z_{i}}{2 \pi f}, 1 \leq i \leq 4 \\
C_{i}=\frac{1}{2 \pi f Z_{i}}, 1 \leq i \leq 4
\end{gathered}
$$

where the characteristic impedance of the transmission lines, $Z_{i}$, is given by Eq. (1).

To further reduce the coupler size of Fig. 4(a), two or three shunt capacitors connected at the same node are combined into a single capacitor. Finally, the complete schematic of the proposed fully-lumped crossover coupler is shown in Fig. 4(b). It consists of ten inductors and eight capacitors. The capacitor

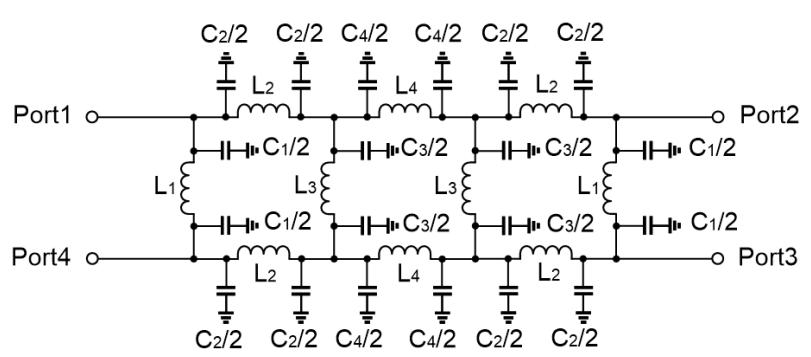

(a)

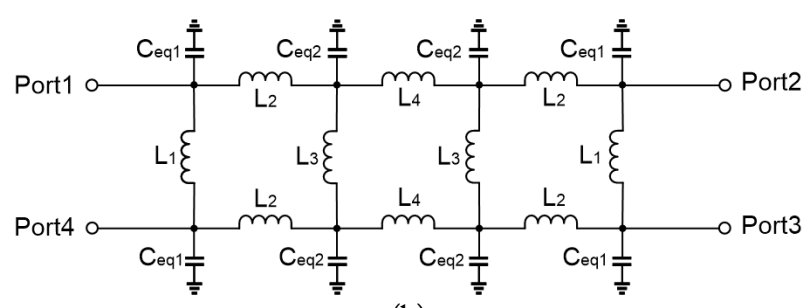

(b)

Fig. 4. Proposed fully-lumped crossover coupler based on threesection branch-line structure: (a) initial version and (b) final version. 
values are given by

$$
C_{e q 1}=\frac{C_{1}+C_{2}}{2}, C_{e q 2}=\frac{C_{2}+C_{3}+C_{4}}{2}
$$

\section{DESIGN OF FulLy-LuMPed CROSSOVER COUPLER}

A crossover coupler is designed at $2 \mathrm{GHz}$, following the proposed fully-lumped structure of Fig. 4(b). The lumped component values are theoretically calculated by Eqs. (1), (4), (6), and are summarized in the left column of Table 1 . However, the theoretical values cannot be practically used for the coupler design and should be further optimized for two reasons.

Firstly, the component values available from commercial chip inductors and capacitors are limited. Thus, the values must be chosen from the set of discrete values available within the chip components.

Secondly, the parasitics of the chip components must be considered for accurate simulation of the coupler performance. It was found that the chip inductors involve relatively large parasitics, so that their operation deviates considerably from those of ideal inductors. Therefore, the chip inductors on the PCB are measured by a network analyzer and then modeled using the equivalent circuit model [11] shown in Fig. 5. $R_{s}, C_{\text {lead }}$, and $C_{\text {sub }}$ represent a parasitic series resistance, inter-lead capacitance, and substrate capacitance, respectively. Fig. 6 shows the measured $S$ parameters of a 3.9-nH chip inductor, compared with the simulation of an ideal inductor and the equivalent circuit model. It is observed that the equivalent circuit model predicts the measurement more accurately than the ideal inductor.

The values of the chip inductors and capacitors are optimized

Table 1. Theoretical and optimized values of the lumped components in the 2-GHz crossover coupler

\begin{tabular}{ccc}
\hline Component & Theoretical value & Optimized value \\
\hline$L_{1}$ & $3.97 \mathrm{nH}$ & $3.3 \mathrm{nH}$ \\
$L_{2}$ & $3.18 \mathrm{nH}$ & $3.9 \mathrm{nH}$ \\
$L_{3}$ & $5.09 \mathrm{nH}$ & $3.9 \mathrm{nH}$ \\
$L_{4}$ & $5.09 \mathrm{nH}$ & $5.6 \mathrm{nH}$ \\
$C_{e q 1}$ & $1.78 \mathrm{pF}$ & $1.8 \mathrm{pF}$ \\
$C_{e q 2}$ & $2.22 \mathrm{pF}$ & $2 \mathrm{pF}$ \\
\hline
\end{tabular}

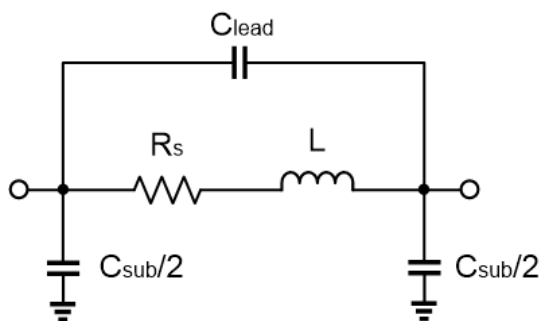

Fig. 5. Equivalent circuit model of chip inductor on PCB.

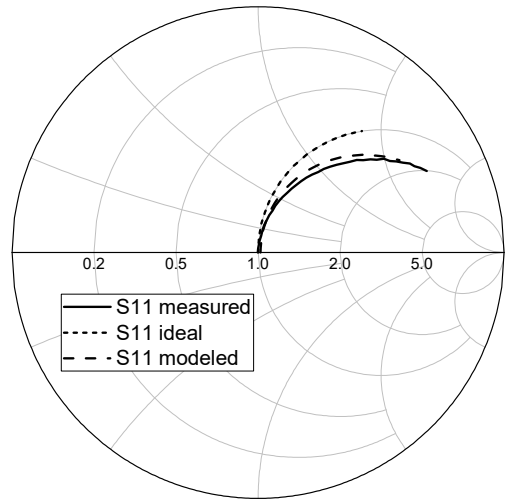

Fig. 6. Measured $S$-parameters of a 3.9-nH chip inductor, compared with the simulation of an ideal inductor and the equivalent circuit model $(f=0-3.5 \mathrm{GHz})$.

in simulation, while considering the two factors aforementioned: one is the discrete selection of commercial chip components and the other is the use of equivalent circuit model including parasitics. The optimized component values are given in the right column of Table 1.

\section{EXPERIMENTAL RESULTS}

A 2-GHz crossover coupler was fabricated on an FR-4 PCB, which has a thickness of $1.6 \mathrm{~mm}$, dielectric constant of 4.7 , and loss tangent of 0.02 at $1 \mathrm{MHz}$. For chip components, WE-MK multilayer ceramic inductors with size of $0603(1.6 \mathrm{~mm} \times 0.8$ $\mathrm{mm})$ and Samsung multilayer ceramic capacitors with size of $0402(1.0 \mathrm{~mm} \times 0.5 \mathrm{~mm})$ were used.

Fig. 7 shows the top view of the fabricated crossover coupler. The size of the crossover coupler (dashed box) is $11 \mathrm{~mm} \times 9$ $\mathrm{mm}$, while $50-\Omega$ feedlines are added to each port for the purpose of measurement. If normalized by wavelength, the size becomes $0.07 \lambda \times 0.06 \lambda$, which is significantly smaller than the conventional crossover couplers based on quarter-wave lines. For example, compared to the three-section branch-line [7] crossover coupler shown in Fig. 2, the size is reduced by $95 \%$.

The measured $S$-parameters are shown in Fig. 8. The insertion loss, isolation, and return loss are $1.7 \mathrm{~dB}, 24 \mathrm{~dB}$, and 14.5 $\mathrm{dB}$, respectively, at $2 \mathrm{GHz}$. The fractional bandwidth achieving

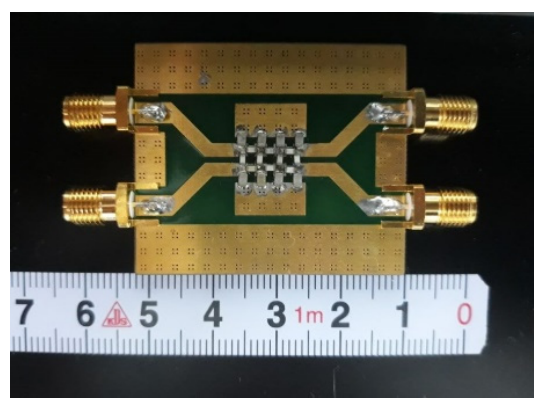

Fig. 7. Fabricated 2-GHz crossover coupler. 


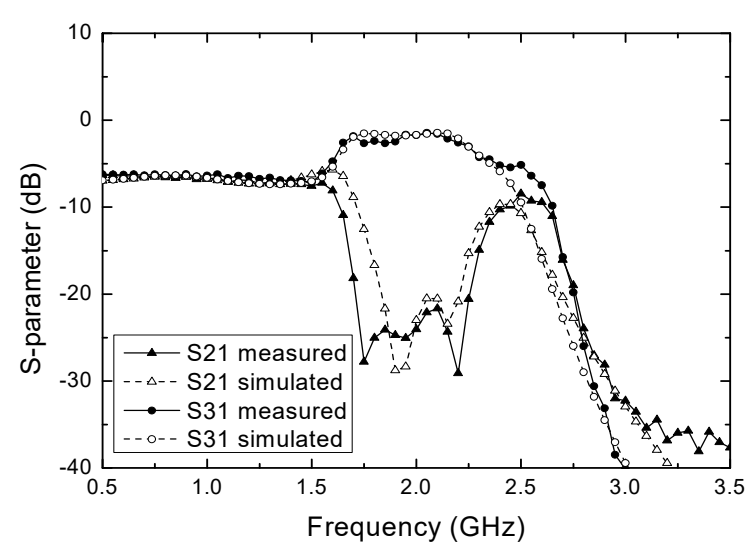

(a)

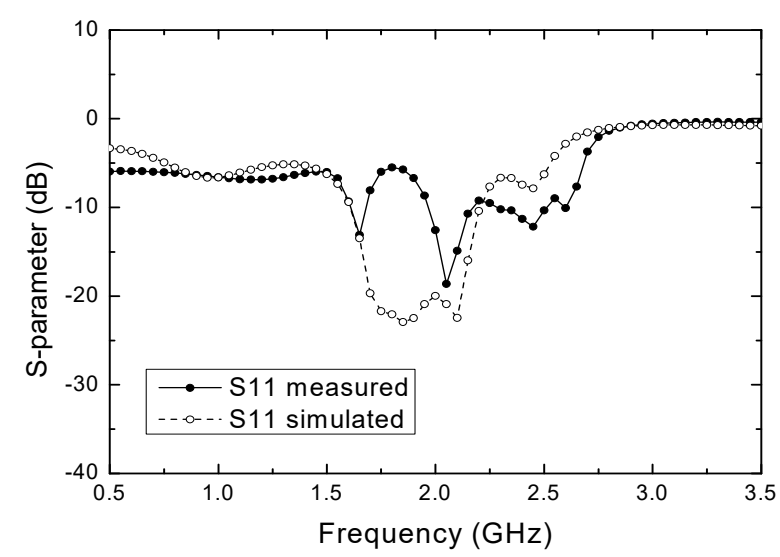

(b)

Fig. 8. Simulated and measured $S$-parameters of the cross-over coupler: (a) insertion loss and isolation and (b) return loss.

both 3-dB insertion loss and $20-\mathrm{dB}$ isolation is $27 \%$ (from 1.71 to $2.25 \mathrm{GHz}$ ). A difference between the simulated and measured return loss is believed to be due to additional model inaccuracy of the lumped components, especially underestimation of capacitance of chip capacitors.

\section{CONCLUSION}

A compact and wideband crossover coupler is implemented using fully lumped components. For wideband operation, a

Table 2. Performance comparison of crossover couplers

\begin{tabular}{ccccc}
\hline Ref. & Core size & $\begin{array}{c}f \\
(\mathrm{GHz})\end{array}$ & $\begin{array}{c}\text { FBW } \\
(\%)\end{array}$ & $\begin{array}{c}\text { RL / IL / ISO } \\
(\mathrm{dB})\end{array}$ \\
\hline$[6]$ & $0.33 \lambda \times 0.16 \lambda$ & 6 & 9 & $20 / 1.0 / 15$ \\
{$[7]$} & $0.45 \lambda \times 0.20 \lambda$ & 2.5 & 40 & $20 / 0.3 / 20$ \\
{$[8]$} & $0.39 \lambda \times 0.18 \lambda$ & 2.5 & 31 & $30 / 0.5 / 27.5$ \\
{$[9]$} & $0.21 \lambda \times 0.18 \lambda$ & 0.8 & 15 & $30 / 0.3 / 20$ \\
& & 1.2 & 10 & $30 / 0.4 / 38$ \\
This work & $0.07 \lambda \times 0.06 \lambda$ & 2 & 27 & $14.5 / 1.7 / 24$
\end{tabular}

$\mathrm{FBW}=$ fractional bandwidth, $\mathrm{RL}=$ return loss, $\mathrm{IL}=$ insertion loss, $\mathrm{ISO}$ $=$ isolation. three-section branch-line structure is employed. In order to reduce the size, the transmission lines are replaced by the $\pi^{-}$ equivalent lumped components. The measured fractional bandwidth for $3-\mathrm{dB}$ insertion loss and $20-\mathrm{dB}$ isolation is $27 \%$, centered at $2 \mathrm{GHz}$. The size of the crossover coupler is only $0.07 \lambda$ $\times 0.06 \lambda$. The performance comparison of the crossover coupler is given in Table 2. The proposed crossover coupler achieves a wide operating bandwidth with a size significantly smaller than others. It should be very suitable for Butler matrix requiring a compact form factor.

This research was supported by the Agency for Defense Development.

\section{REFERENCES}

[1] F. I. Shaikh and S. B. Akhade, "Smart antenna system using $4 \times 4$ Butler matrix switched beam network for $2.4 \mathrm{GHz}$ ISM band," International Journal of Application or Innovation in Engineering \& Management, vol. 4, no. 3, pp. 278-282, 2015.

[2] T. S. Horng, "A rigorous study of microstrip crossovers and their possible improvements," IEEE Transactions on Microwave Theory and Techniques, vol. 42, no. 9, pp. 1802-1806, 1994.

[3] W. Liu, Z. Zhang, Z. Feng, and M. F. Iskander, "A compact wideband microstrip crossover," IEEE Microwave and Wireless Components Letters, vol. 22, no. 5, pp. 254-256, 2012.

[4] Y. Chen and S. P. Yeo, "A symmetrical four-port microstrip coupler for crossover application," IEEE Transactions on $\mathrm{Mi-}$ crowave Theory and Techniques, vol. 55, no. 11, pp. 24342438, 2007.

[5] C. W. Tang, K. C. Lin, and W. C. Chen, "Analysis and design of compact and wide-passband planar crossovers," IEEE Transactions on Microwave Theory and Techniques, vol. 62, no. 12, pp. 2975-2982, 2014.

[6] J. S. Wight, W. J. Chudobiak, and V. Makios, "A microstrip and stripline crossover structure," IEEE Transactions on Microwave Theory and Techniques, vol. 24, no. 5, p. 270, 1976.

[7] J. Yao, C. Lee, and S. P. Yeo, "Microstrip branch-line couplers for crossover application," IEEE Transactions on Microwave Theory and Techniques, vol. 59, no. 1, pp. 87-92, 2011.

[8] J. Verdu, E. Bernaola, and P. de Paco, "A compact microstrip crossover based on capacitively-loaded artificial transmission lines branch-line sections," Progress In Electromagnetics Research Letters, vol. 68, pp. 121-126, 2017.

[9] F. L. Wong and K. K. M. Cheng, "A novel, planar, and 
compact crossover design for dual-band applications," IEEE

Transactions on Microwave Theory and Techniques, vol. 59, no. 3, pp. 568-573, 2011.

[10] D. M. Pozar, Microwave Engineering. Hoboken, NJ: John

\section{Kwangwon Park}

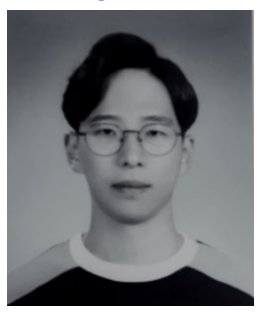

received the B.S. degree from the School of Electrical Engineering, Korea University, Seoul, Korea, in 2018, and is currently working toward the M.S. degree at the School of Electrical Engineering, Korea University, Seoul, Korea. His research interest includes millimeter-wave integrated circuits and systems.

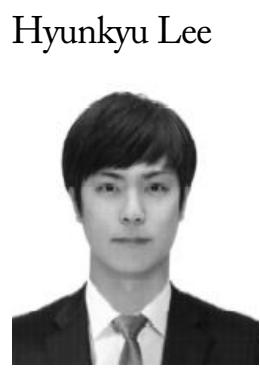

received the B.S. degrees in the electrical engineering from Korea University, Seoul, Korea, in 2014, and is currently working toward the Ph.D. degree at the School of Electrical Engineering, Korea University, Seoul, Korea. His research interest includes microwave and millimeter-wave integrated circuits and transceiver systems.

Iljin Lee

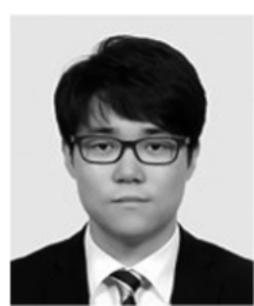

received the B.S. degrees in the electrical engineering from Korea University, Seoul, Korea, in 2013, and is currently working toward the Ph.D. degree at the School of Electrical Engineering, Korea University, Seoul, Korea. His research interest includes millimeter-wave and terahertz integrated circuits and systems for broadband communication applications.

Wiley \& Sons, 2005.

[11] S. Stalf, "Printed inductors in RF consumer applications," IEEE Transactions on Consumer Electronics, vol. 47, no. 3, pp. 426-435, 2001.

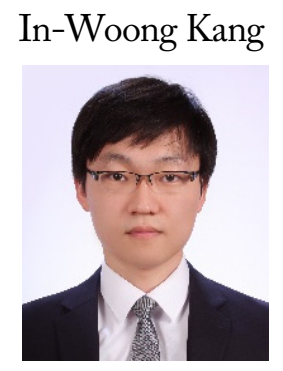

received the B.S. and Ph.D. degrees in electronic and electrical engineering from Pusan National University, Busan, Korea, in 2011 and 2017, respectively. Since 2017, he has been with the 2nd R\&D Institute of Agency of Defense Development of Korea as a Senior Researcher. His primary research interests are in the area of digital signal processing, radio propagation, and spectrum management.

Sanggeun Jeon

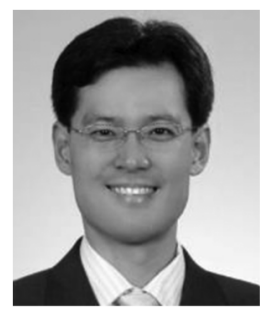

received the B.S. and M.S. degrees in electrical engineering from Seoul National University, Seoul, Korea, in 1997 and 1999, respectively, and the M.S. and $\mathrm{Ph} . \mathrm{D}$. degrees in electrical engineering from the California Institute of Technology (Caltech), Pasadena, CA, USA, in 2004 and 2006, respectively. From 1999 to 2002, he was a full-time instructor in electronics engineering at the Korea Air Force Academy. From 2006 to 2008, he was a Research Engineer in the Caltech High-Speed Integrated Circuits Group, where he was involved with CMOS phased-array receiver design. Since 2008, he has been with the School of Electrical Engineering at Korea University, Seoul, Korea, where he is currently a professor. His research interests include integrated circuits and systems at microwave, mm-wave, and terahertz bands for high-speed wireless communication and high-resolution imaging applications. 